\title{
La expansión de la celda: experiencia estética en la novela La cárcel de Jesús Zárate Moreno*
}

\author{
Frank Orduz Rodríguez
}

Recibido: 4 de diciembre del 2018

Evaluado: 17 de enero de 2019

Aceptado: 25 de febrero del 2019

Citar como: Orduz Rodríguez, F. (2019). La expansión de la celda: experiencia estética en la novela $L a$ cárcel de Jesús Zárate Moreno. Hallazgos, 16(32), 109-129. DOl: https:/l doi.org/10.15332/2422409X.5091

\section{Resumen}

En este artículo se examina la construcción literaria de la experiencia estética dentro de la novela La cárcel (1972), del autor colombiano Jesús Zarate Moreno. El análisis se fundamenta en los acercamientos teóricos sobre la experiencia estética -de Immanuel Kant, Jan Mukařovský y Robert Jauss, entre otros- y el planteamiento teórico sobre el absurdo de Gilles Deleuze. Así, se propone estudiar cómo el personaje principal, Antón Castán, reformula a través de sus posibilidades imaginativas y sensibles su estadía en prisión. Esto se muestra a través de una escritura desintelectualizada a modo de diario personal, en donde se dejan leer distintos mecanismos y operaciones de la sensibilidad en la desintegración del instante.

Palabras clave: novela, La cárcel, experiencia estética, absurdo. 


\section{The expansion of the prison cell: aesthetic experience in the novel La cárcel by Jesús Zárate Moreno}

\begin{abstract}
In this article the literary construction is examined of the aesthetic experience within the novel La cárcel (1972), by Colombian author Jesús Zarate Moreno. The analysis is based on the theoretical approaches on aesthetic experience - by Immanuel Kant, Jan Mukařovský and Robert Jauss, among others - and the theoretical approach on the absurdity by Gilles Deleuze. Thus, it proposes to study how the main character, Antón Castán, reformulates his stay in prison through his imaginative and sensitive possibilities. This is shown through a de-intellectualized writing in a personal diary, in which different mechanisms and operations of sensibility in the disintegration of the instant can be read.
\end{abstract}

Keywords: Novel, La cárcel, aesthetic experience, absurd.
Received: december 4, 2018

Evaluated: january 17, 2019

Accepted: february 25, 2018 


\section{A expansão da cela: experiência estética no romance La cárcel de Jesús Zárate Moreno}

Recebido: 4 de dezembro de 2018 Avaliado: 17 de janeiro de 2019 Aceito: 25 de fevereiro de 2019

\section{Resumo}

Neste artigo examina-se a construção literária da experiência estética dentro do romance La cárcel (1972), do autor colombiano Jesús Zarate Moreno. A análise fundamenta-se nas aproximações teóricas sobre a experiência estética - do Immanuel Kant, Jan Mukařovský e Robert Jauss, e outros- e a exposição teórica sobre o absurdo do Gilles Deleuze. Assim, propõe-se estudar como o personagem principal, Anton Castán, reformulada através de suas possibilidades imaginativas e sensíveis na sua estadia na prisão. Isto se mostra através de uma escritura desintelectualizada como diário pessoal, no qual se deixam ler distintos mecanismos e operações da sensibilidade na desintegração do instante.

Palavras-chave: romance, La cárcel, experiência estética, absurdo. 
"Desintegrado el átomo, hacía falta que yo desintegrara el instante".

Jesús Zárate Moreno (La cárcel)

"Y lo que a la humanidad entera le está dado, quiero gozarlo en lo más recóndito de mí mismo".

Fausto Goethe (Fausto)

\section{INTRODUCCIÓN}

Para algunos solitarios de la literatura colombiana, aún luego de su muerte, les ha sido difícil surgir a causa de la sombra de autores que han alcanzado gran reconocimiento y que en algunos casos se han convertido en escritores de culto. Es el caso de autores como Eduardo Zalamea Borda que fue gran damnificado por Mito -a pesar de su colaboración en la revista del mismo nombre-, o de Héctor Rojas Herazo, ocultado por la monumental figura de Gabriel García Márquez, (aunque a todo el grupo de Barranquilla le costó su ascenso). Un asunto particular es el de Jesús Zárate Moreno, autor santandereano que, inmiscuido en el campo de la política colombiana, afín a la esfera literaria de las décadas del cuarenta y cincuenta, no contó en el ámbito nacional de las letras con el impulso que sí tuvieron escritores de grupos como los Piedra y cielo, entre los que destacaba su amigo Tomás Vargas Osorio. Fueron, precisamente, los piedracielistas y Mito los que marcaron la entrada de la literatura colombiana a un perímetro de mayor libertad con respecto a las fórmulas heredadas del naturalismo y el modernismo rubendariano.
Sin embargo, no se debe desconocer que hay una gran deuda literaria con el escritor santandereano Jesús Zárate Moreno. Su obra, disímil por los saltos entre lo rural y lo existencial, merece mayores acercamientos, no para caer en servilismos críticos, sino para reconocer que su trabajo narrativo, una isla inexplorada, ayuda a comprender una estética que indaga los remotos espacios de la vida humana, desde el humor y el absurdo $^{1}$. Es así que al leer la obra del autor, se estiman problemas como el examen de la culpa, la memoria y la experiencia profunda del mundo, además de cuestiones que tienen que ver con la política y algunas conductas sociales y culturales.

Sus novelas La cárcel (1972) y luego El cartero (1973) -dos piezas extrañas en el momento en que el fenómeno de La Violencia cobraba líneas en las estanterías-, construyen un universo distinto al de sus cuentos, pues su creación literaria adquiere tonalidades del absurdo, remarca la experiencia individual y amplía la concreción del instante. Este escrito se centra en el examen de la experiencia estética que el autor santandereano literaturiza en su novela $L a$ cárcel, particularmente en el primer apartado de la novela intitulado "La rata"

1 En un trabajo anterior sobre la novela La cárcel, junto a la investigadora Yésica Andrea Nieto Lascarro -El metateatro en La cárcel de Jesús Zárate Moreno: un proceso a la justicia (2017)-, se propone un recorrido por algunas historiografías de la literatura colombiana, en donde se menciona la importancia del autor santandereano. Cabe resaltar que en el rastreo, el nombre de Jesús Zárate Moreno, como las ponderaciones sobre sus cuentos, relatos, piezas teatrales y novelas, no solo reciben la admiración de los analistas, sino que su aparición y estima se mantienen a través del tiempo, elemento que manifiesta su calidad e invitación a ser visitado.

2 Precisamente, Diego Higuera Moreno, en su texto Antón Castán y las representaciones del intelectual en La cárcel, de Zárate Moreno (2013), plantea que en la primera parte de la novela Antón Castán se aísla del mundo y sus reflexiones son abstractas, pues son divagaciones sobre la justicia y la libertad (p. 25). En el esquema trazado 
Alrededor de temas como la justicia, la libertad, el recuerdo, la infancia, entre otros, la novela La cárcel muestra las posibilidades que el sujeto tiene de concebir formas y de modelar un universo, que le permite una existencia llena de significado y de sentido al interior de una prisión. Así, la actitud intrínseca de los personajes de La cárcel es la de incidir o modificar su realidad, pues la revaloran y abordan desde una nueva óptica, a la vez que generan imágenes nuevas del mundo como nuevas formas de estar y hacer en él. Esta constante re-significación que hacen los personajes, proyectada en imágenes de gran riqueza simbólica, se convierte en un ejercicio sistemático a lo largo de la novela -sobre todo en su primera parte- que permite a los personajes sustentar su pasado y presente.

Desde esta perspectiva que plantea Jesús Zárate Moreno, la experiencia estética dentro del universo de La cárcel se puede abordar desde algunos acercamientos canónicos acerca de este problema del arte y de la filosofía. En primera instancia, los acercamientos de Immanuel Kant, Jan Mukařovský y Hans Robert Jauss al asunto de la experiencia estética permiten pormenorizar un tipo de relación entre el sujeto y el mundo, dentro de los límites de la sensibilidad y la imaginación. En segundo lugar, los acercamientos de Giles Deleuze sobre el absurdo, otorgan renglones oportunos para examinar cómo los personajes de La cárcel reformulan su estadía en prisión y crean paradojas entre lo dado y lo creado. Estos acercamientos teóricos permiten leer la novela del santandereano como

por Higuera Moreno, tales cavilaciones son experiencias de orden sensible y por lo mismo abstractas. Esta afirmación es una muestra de cómo opera la subjetividad del personaje en la reelaboración de su vida en prisión. una reflexión profunda sobre las posibilidades imaginativas del ser humano y su incidencia en el mundo, elemento llamativo y raro en la literatura colombiana de su tiempo -pues fueron pocas propuestas estéticas las que en tiempos de La Violencia blandieron sus problemáticas desde perspectivas psicológicas, rompiendo con el realismo literario de este período- ${ }^{3}$.

\section{EXPERIENCIA ESTÉTICA Y RUPTURA DE LAS CONVENCIONES}

La vocación de dramaturgo de Jesús Zárate Moreno pone al lector frente a una obra sumamente gráfica; esto no lo determina las descripciones de personajes y espacios, como sí la abundancia de diálogos que otorgan una imagen mental de los sujetos y de sus evocaciones ${ }^{4}$. Claramente lo que sucede en novelas como La cárcel o El cartero, para contextualizar mejor, es que se está frente a una expansión de la experiencia del sujeto. Lo anterior propone una escritura dotada de una corporeidad sensitiva y volitiva, que se fortalece con los imaginarios que proyecta, desde el punto de vista narrativo.

Desde la cárcel es curioso observar a los hombres en los cafés. A simple vista, se saca la deducción de que la libertad suele pasearse el día en los cafés. Fijándose detenidamente, los hombres

3 Al respecto, Luis Rubén Pérez Pinzón, en su texto "Literatura santandereana. Visibilidad, concepciones y evocaciones" (2018), ubica en el campo de la literatura regional santandereana a Zárate Moreno y a Tomás Vargas Osorio como reinterpretes del costumbrismo regional en Colombia. (P. 143).

4 De hecho, la presentación de la primera edición santandereana de La cárcel (2016), dirigida por la Fusander y la Universidad Industrial de Santander, resaltan que la novela cuestiona el pensamiento convencional acerca de la inocencia, la condena y la culpa, a través de un lenguaje contemporáneo, configurándose como una novela cinematográfica. 
parecen presos también, atados a las sillas donde se sientan y a las mesas frente a las cuales beben o comen o conversan. Aunque es muy temprano aún, no falta quien tome aguardiente a esta hora. Los que lo hacen tan temprano beben el aguardiente en tazas de café, de modo que todo se cumple con arreglo a las más severas exigencias de la moral pública. Pero la mayoría de los clientes beben café, en pequeñas tazas que humean a lo lejos, en la bruma, como chimeneas de barcos de juguete. (Zárate Moreno, 1980, p. 151).

Desde la cárcel, los presos del café resultan bastante tristes. Viven de pequeños hartazgos de pereza y de ilusión. Murmuran y hablan de lo que no entienden, como de la guerra y la política. Subyugan y dominan a las mujeres que no tienen. Llenan de vida miserable la muerte que se les hincha en las rodillas. Cuando no están calumniando, chillan y se quejan de los impuestos del Gobierno. Se hacen limpiar los zapatos incansablemente, hasta que les arden los pies. Embalsamadas en el olor del café, estas momias de la libertad dan idea muy pobre de la libertad. (P. 152).

Esta expansión evocativa y desglosamiento de parcelas de la realidad, narrada de una forma tan teatral, puede extraviar el carácter epistemológico que guarda una de las obras más heterónomas de la literatura santandereana. Las disertaciones sobre los distintos temas presentados en la novela como sus cómicos tratos, dados por la licencia y soltura de los personajes, pueden distraer la trascendencia subjetiva de tales situaciones. Sin embargo, el lector se encuentra frente a una novela que se aleja del fenómeno de La Violencia -el caudillismo, la vida dentro de la guerra, la ficción histórica-, se aparta de cualquier pretensión naturalista y realista e incursiona en la subjetividad de los habitantes de la cárcel. Justamente, la novela soporta esta cuestión desde la exposición que Antón Castán, personaje principal de la novela, hace en su diario sobre la actividad cotidiana de la prisión, al lado de sus compañeros de encierro: Mister Alba, David Fresno, Braulio Coral y Antonio Tudela, "el Honorable Gordo Tudela".

De hecho, la intención de escribir una novela a modo de diario ya determina, además de un pacto de lectura, una intención estética que proyecta una experiencia de la misma índole. La escritura y la lectura del diario de Castán ofrecen una reinterpretación desintelectualizada de su experiencia, fundada más que en la lógica de algunas de sus disertaciones, en una sensibilidad de carácter estético. Así, el concepto de experiencia estética que opera en la trama de la obra se deslinda de la experiencia del arte y se posiciona en la concesión de adiciones de sentido que un sujeto da a otro objeto de su percepción.

Según Mukařovský (1977), cualquier objeto o acción, cualquier producto de la actividad humana, pueden ser portadores de un valor estético. Para el crítico y teórico checo, un objeto o una acción no son portadores intrínsecos de tal valor, pues es el sujeto quien adopta una posición sobre los objetos y estos le revelan su relación íntima con la realidad: allí "la cosa" se convierte en signo estético (1977, p. 148). Esta operación de atribución y retribución que experimenta el sujeto en relación al objeto, es lo que Kant (2000) llama sensibilidad. Esta consiste en una suerte de sentido interno por el cual el 
psiquismo se distingue y obtiene una intuición del alma como objeto. En ese sentido, espacio -condición externa- y tiempo -condición interna- como dimensiones de la subjetividad, como intuiciones puras, proporcionan representaciones de los objetos de la sensibilidad.

Si bien lo que se conoce de los objetos son meras representaciones, no los objetos en sí, el conocimiento a priori, según Kant, apela a unos límites donde los objetos son cognoscibles como fenómenos. Kant no desconoce que hay en las cosas una esencia real (co-relato) que, aunque no puede ser conocida objetivamente, está en todas las proyecciones que hace el sujeto de ellas. Entonces, la experiencia sensible es a un tipo de saber en el que la subjetividad, como fuente de conocimiento, proporciona el carácter de los objetos como fenómenos, inscrito meramente en los sujetos. Y aunque en el fenómeno yace lo que le es inherente a un objeto y que puede ser válido para todo sentido humano, su condición esencial no es totalmente asequible. Es por eso que solo se distingue lo que corresponde particularmente a la intuición, que no es válido para la sensibilidad en general y sí para la posición especial de determinada intuición (2000, pp. 87-89).

Esto es interesante: esta clase de conocimiento, más que poseer principalmente una función práctica, otorga, según Hans-George Gadamer (1996), un "trastorno y derrumbamiento de lo acostumbrado", ya sea como experiencia del arte o como experiencia cotidiana. Y así como el arte le dice al sujeto "eso eres tú" y a la vez lo increpa: "debes cambiar tu vida" (p. 10), la realidad puede no realizar directamente estos dos señalamientos como sí generarlos a partir de la actividad imaginativa del sujeto. En tales circunstancias, si una cosa de la realidad se le presenta al sujeto como él mismo y como cambio, el trastorno y derrumbamiento de lo acostumbrado es consecuencia de una condición primaria, esa que Otto $\mathrm{Ri}$ cardo (2003) llama el mundo en $m i^{5}$, es decir, la construcción subjetiva de la realidad y su concreción como signo estético.

Tal signo estético, dice Mukařovský (1977), sugiere un conjunto de realidades que el sujeto ha podido y podrá vivir. El objeto o fenómeno de la realidad que adquiere la función estética, está orientado a ver el mundo de una forma particular. A pesar de estar ligado a unos valores predeterminados, se desliga de su referente práctico, cognoscitivo y utilitario, en donde el objeto portador de la función estética tiene valor en sí mismo. Este punto es evidentemente cercano a la propuesta kantiana acerca del conocimiento a priori y la relación sensible entre sujeto-objeto. Pero a pesar de no tener en esencia una función práctica, esta función estética adquiere importancia si se le haya su trascendencia en la vida cotidiana. De hecho, Mukařovský explica que frente a un universo de fines prácticos y unifacéticos, la lucha diaria del sujeto con la realidad puede, y es necesaria, que se aborde desde perspectivas $u$ ópticas nuevas, capaces de descubrir propiedades y posibilidades inaprovechadas hasta su encuentro. Esta función desautomatiza la realidad y busca posar su atención sobre lo conquistado, sobre sí mismo y sobre un escenario que le descubre regiones desconocidas e inagotables.

5 En su análisis sobre el poema "Aldea", de Darío Samper, Otto Ricardo Torres propone que en la percepción estética el sujeto compromete su sentido de sentir, es decir, su subjetividad y por consiguiente resulta el mundo en mí. Esto procura que determinado elemento de la percepción revele dimensiones como la identidad, al alma y la ideología al sujeto. 
Por su parte, y de una forma esquematizada, Hans Robert Jauss propone en su Pequeña apología de la experiencia estética (2002) que este tipo de vivencia es siempre liberación de sentido. Desde lo expuesto en la doctrina aristotélica de la catharsis, Jauss plantea que la experiencia estética, como conocimiento de lo bello, opera en la medida en que el espectador se libera de los intereses prácticos sobre los objetos de la realidad. Es por eso que en este tipo de experiencia el sujeto advierte un mundo como su propia obra (poiesis), aprovecha las posibilidades de percibir el mundo de otras formas (aisthesis) y se identifica y crea puentes intersubjetivos a partir de dicha percepción (catharsis) (pp. 41-42).

Precisamente, en la novela La cárcel, Zárate Moreno recurre a las recreaciones que hacen los personajes de su espacio y tiempo, estas que resultan como derivado de su actividad imaginativa y que en muchas ocasiones y pasajes de la novela solo tienen un fin en sí mismas:

El Honorable Gordo Tudela ha desaparecido. En la sombra sólo se ven los dos palos que sus manos frotan con furia diabólica. Lo que sale de sus manos es una música amasada con los orígenes del fuego. Antes de ser música, debió ser un rito sagrado, una explosión de calor elemental. (Zárate Moreno, 1980, p. 146)

La cárcel sería otra cosa si aquí los hombres no declamaran tanto. La poesía merece mis homenajes. Ante ella me descubro. Pero ante el recitador no me descubro, porque el recitador es un traidor de la lírica, un ventrílocuo de la poesía. (P. 147).
Entonces la cárcel, centro de reclusión, como construcción paradojal, se convierte en un espacio de libertad y de posibilidades inimaginables y sensibles. Desde la cita anterior, como desde las primeras líneas del diario de Antón Castán, en la novela se presenta una intención estética que rompe con los principios de identidad de su creador, como de las imágenes y conceptos que se le revelan. En lo que sigue de este texto se verá cómo el autor santandereano propone una escritura desintelectualizada de la vivencia y los distintos estratos de la experiencia estética.

\section{EL DIARIO COMO INTENCIÓN ESTÉTICA Y UN GÉNERO PARA MENTIR BIEN LA VERDAD}

La escritura de un diario como forma dentro de una novela requiere verse, inobjetablemente, como comunicación estética. Hans Rudolf Picard en su texto "El diario como género entre lo íntimo y lo público" (1981), plantea que el diario en la literatura aparece cuando un sujeto dentro de la ficción tiene la imposibilidad de comunicar: lo que es no-comunicación se convierte estéticamente en comunicación. A su vez, si el diario es el escenario que posibilita lo que en virtud no se podría fuera de la novela, este espacio adquiere una función teatral, donde el ademán de privacidad se rompe debido a la presencia de un lector virtual. En ese caso el diario dentro de la obra literaria se convierte en presentación, que ligada al concepto de intimidad realza por antonomasia la particularidad del texto literario, pues visibiliza las estructuras de la intimidad de los objetos que aprehende (pp. 119-120).

Si se sigue a Hans Rudolf Picard sobre la aprehensión del diario como escritura estética y 
leemos La cárcel de Jesús Zárate Moreno, se observa que esta escritura literaria se da en una superposición de escrituras estetizadas. En primer lugar, está la escritura de Zárate Moreno, claramente autor-contractual de la novela; luego la de Antón Castán, autor-ficticio del diario. Como en toda obra literaria, y más en la que usa el diario como sustento de su trama, el autor-contractual es relegado por el autor-ficcional, esto en la medida en que su escritura crea a otros personajes y su visión supera los tintes de lo visual-anecdótico para plantear, desde distintos artificios narrativos, una construcción de corte literario. Esto no es lo particular de la novela en cuestión, pues es un principio intrínseco de toda creación literaria, pero lo que sí interesa es que de entrada Zárate Moreno echa mano de este artilugio literario para exponer las puntadas de su creación. La doble intención estética de la novela muestra en principio una vida imaginada y la imaginación de esa vida: “Mi nombre es Antón Castán. En realidad, me llamo Antonio Castán. Pero en la escuela, siendo muy niños, por una concesión cordial, mis compañeros decidieron despojar la palabra de las dos últimas letras" (Zárate Moreno, 1980, p. 7).

La presentación del autor del diario como un yo, un yo modificado por su propia voluntad, parodia el principio autobiográfico de ruptura con el sistema que lo cohíbe y le impide comunicar algo. Al respecto, Paul de Man, en "La autobiografía como desfiguración" (1991), expone que una escritura que insiste en la temática del sujeto, en la de su nombre, la memoria, su procedencia, el eros y la muerte, muestra un ansia de escapar de las coerciones impuestas de un sistema (1991, p. 114). En correspondencia con la novela, el encuentro con un diario dentro de la obra literaria y a manos de un escritor ficticio, que reflexiona sobre la alteración de su ser, la búsqueda de lo que realmente puede llegar a ser este escritor-ficticio está supeditada por lo que debe transgredir. Así, el quebrantamiento del sistema que limita al escritor del diario es en cierta medida una reinvención de su ser, que en La cárcel va desde la fundación de su nombre, pues lo identifica como un "hombre de letras, como se decía antiguamente para calificar lo que implicaba una actividad intelectual" (Zárate Moreno, 1980, p. 8). Empero, más que la disertación sobre su identidad, su actividad diarística muestra el afán de exponer el único modo que le queda a Antón Castán para ser libre: la escritura.

Es por eso que para Antón Castán su nombre mutilado le figura una actitud particular frente al mundo, cuestión que interesa en el estudio de la experiencia estética pues, como ya se ha mencionado, el surgimiento de una experiencia de este tipo demanda una afirmación del yo y una actitud especial de la sensibilidad. Por otro lado, hay otro indicio de la intención estética de la escritura del diarista: la elección de un género propicio para transportar su visión de mundo. Claramente, su elección del género es de antemano una preocupación por la incomunicación que se ha erigido entre él y el mundo, no obstante situaciones de incomunicabilidad son las que llevan, en muchos casos, a la escritura de un género como el diarístico:

La inquietud de escribir algo me acosaba desde hacía varias semanas, aunque no lograba decidirme sobre el medio que debía adoptar para consignar mis pensamientos y ordenar mis experiencias y recuerdos. El verso exige un don de profecía cósmica del que yo carezco. 
La novela es un espejo en un camino, como dijo Stendhal, y en la cárcel no hay espejo ni camino. El teatro sería más adecuado, pero el teatro imita tan mal la realidad, que el teatro me da siempre más miedo que la vida. Las memorias son una venganza de los estadistas en decadencia o una coquetería de las relaciones públicas de las damas galantes. El ensayo es filosofía periodística, algo así como decir religión irreligiosa.

No me quedaba más recurso que el diario. Y no me arrepiento. A pesar de estar desacreditado también, el diario es el instrumento de la expresión más honesto, porque es el único que desde el principio se sabe que no es sincero. No pretende adivinar, como el verso, ni colabora en la locura, como la novela, ni aspira a suplantar la verdad, como el teatro, no se maquilla el rostro, como las memorias, ni posa de pedante, como el ensayo. Participa, sin embargo, de los ingredientes de todos esos estilos, los buenos y los malos, aunque bien dosificados. Entre todos ellos, el diario es la manera más inofensiva de mentir.

Además, siendo la cárcel tan verdadera y tan falsa como la misma literatura, el diario es por excelencia el género literario para presos. No es muy exigente que digamos. No impone pensar, sino llenar de palabras la soledad y el silencio [...]. (Zárate Moreno, 1980, pp. 11-12).

La reflexión que hace Antón Castán acerca del género es la puerta y línea de seguimiento para los acontecimientos que se narran en la novela y su modo de ser leídos. Como forma narrativa Castán le da al diario el híbrido status de literario, asunto en el que es categórico al presentarlo como una forma "inofensiva de mentir". Pero lo que interesa es que más que mentir o lograr transportar sus pensamientos y acontecimientos en prisión, la preocupación del autor del diario es determinar su relación con el mundo y consigo mismo: la elección del diario viene de su condición de presidiario. Además, la adopción del género es una obligación para el personaje, es un deber ser y proceder, por lo que todo allí adquiere un carácter especial que no busca la verdad de una vida sino la verdad de un alma, de una experiencia que desea completar con palabras, de una experiencia que escudriña ser colmada con un gesto distinto al mundo que lo rodea: el de una escritura orgánica, capaz de conciliar las partes del mundo que lo conmueven.

La siguiente selección de frases de Mister Alba muestra una vértebra común. Por eso la salvo para ser intercalada en el diario, con mucha complacencia de mi parte y con benevolencia del autor. Y ello porque el hilo que une estas ideas es el tema que a mí mismo me obsesiona: la libertad, la justicia, la cárcel. (Zárate Moreno, 1980, p. 225).

En consecuencia, tanto iniciativa de escritura como vivencia escrita van a tener un carácter de adición, ya sea por la condición y actividad propia del escritor como también por la proyección de una visión particular. En dicha escritura el carácter estético saca provecho del recuerdo y de la sensación, elemento que enriquece cada una de las imágenes que Antón Castán resalta. En este caso, se tomarán algunos de los momentos de la escritura del diario en donde la vivencia de su autor muestra un derrumbamiento 
de lo acostumbrado y cada momento es enriquecido, aprovechado y desautomatizado en una inmersión de posibilidades que le manifiestan a Castán su propio ser.

\section{"Ahí está el zapato", "Ahí tenéis Al hOMbre" O ANOCHECER COMO RATA: EXPERIENCIA ESTÉTICA COMO FUNCIÓN DEL YO}

Luego de presentarse como un sujeto que por necesidad ha aceptado los cambios de su identidad y luego de la reflexión sobre el género portador de sus pensamientos, en el tercer día del diario, "Viernes. Octubre 16", Antón Castán comienza, después de una breve observación espacial, con una aserción aparentemente insustancial: "Ahí está el zapato" (Zárate Moreno, 1980, p. 14). Esta afirmación es justamente una seña indiscutible de la desautomatización que la presencia de un simple zapato propone a la sensibilidad de Castán. Como un milagro, la aparición del zapato que se movía por "sí sólo"6 rompe con una larga temporada en el "letargo del encierro". Es la misma descripción del autor del diario la que metaforiza esta sensación de novedad como “(...) la puerta a la poesía, la promesa de libertad, el halago del ensueño; el escape, en fin, hacia todo lo que la cárcel me había robado" (1980, p. 14-15).

En principio, dicha puerta a la poesía, a la promesa y al ensueño es sin duda en términos de recepción estética (aisthesis), una invitación a que el espectador "participe en el proceso de una nueva constitución del mundo...", a que se haga "(..) cargo así

6 Por cuestiones de respeto con la edición que se cita, se encontrarán tildes en palabras que hoy en día ya no necesitan de ella. de la posibilidad de que «las cosas se vayan constituyendo en su aparición»" (Jauss, 2002, p. 70). Es por eso que el autor del diario comenzará, luego de advertir el zapato, a percibir unas cualidades que van más allá del objeto de su visión.

Movimientos de atribución de sentido como este referidos en el diario empiezan a marcar una vectorialidad que permite explicar un tipo de experiencia no medible, pero sí cualificable. La descripción de Castán propone un movimiento que va desde el desconocimiento de su espacio como de su ser, hasta la afirmación y conocimiento involuntario de sí mismo. "Ahí está el zapato" es probablemente una afirmación cósmica que lo determina como un sujeto distinto, único e irrepetible, aunque parcialmente consciente de su particularidad. Como la frase proferida por Pilatos al lavarse las manos frente a Jesucristo, "ahí tenéis al hombre", Castán señala el zapato y advierte su presencia mágica y límpida. "Ahí está el zapato" puede ser el equivalente de "ahí tenéis al hombre", ese mismo con el que Nietzsche intitula uno de sus textos más reveladores y autobiográficos: Ecce Homo (1908).

Tanto el narrador del Ecce Homo como el narrador de La cárcel, tienen una particularidad: a pesar de ver en la escritura una posibilidad de contestar a algunos de sus interrogantes vitales, Nietzsche, en Ecce Homo, y Castán, en su diario, desde sus registros particulares, se encuentran con la limitación de llegar a saber lo que se es. Al respecto argumenta el primero:

Al llegar a este punto no puedo dejar de contestar a la pregunta de cómo llega a ser lo que se es. Y con ello me refiero a esa obra maestra en el arte de 
la autoconversación que es el egoísmo. Como, efectivamente, la tarea, la determinación, el destino superan en mucho la talla ordinaria, no hay peligro mayor que el de enfrentarse cara a cara con dicha tarea. Llegar a ser lo que se es presupone no tener ni la más mínima idea de lo que se es. (Nietzsche, 2004, p. 48).

Por su parte, el diarista de La cárcel no hace esta afirmación en un ejercicio directo de lucidez, pero sí advierte en sus conclusiones que la aparición del zapato significa un cambio en él, que no tiene una explicación más que la fantasía que causa la presencia del zapato. El diálogo con Nietzsche es interesante en la medida en que el hilo de sus disertaciones los lleva al descubrimiento de las costuras de sus humanidades, aun cuando muestran lo experimental de su método. Castán, sin mayores pretensiones, es iluminado por un objeto inanimado que le muestra algunas de sus posibilidades en el mundo y la restauración de algo perdido, o quizá algo nunca antes sido: "Puesto que existía un misterio yo volvía a ser un hombre, y no cualquier hombre, sino un ser atraído a lo inexplicable por el hilo maravilloso de la fantasía" (Zárate Moreno, 1980, p. 15). La gravitación entre el ser este "hombre" y la atracción a lo inexplicable por "el hilo maravilloso de la fantasía", pone de manifiesto la cuestión sobre la perturbación de la realidad y su carácter involuntario. Justamente es así como opera lo fantástico, pues esto causa un desajuste en la percepción e irrumpe en el orden habitual ${ }^{7}$.

Es bueno precisar, como lo hace Todorov en su Introducción a la literatura fantástica (1981), que lo fantástico, además del desajuste de la realidad, acepción que toma de Roger Callillos (1965), también es un modo de lectura. Tal posición de lectura propone un vínculo entre el mundo real que puede vacilar entre lo natural y lo sobrenatural,
Y si lo fantástico opera como forma que proyecta un cambio y un desajuste de la realidad, en lo que toca a la experiencia estética, la visión particular que tiene Antón Castán con el objeto -zapato- le revela su vínculo con la realidad, desde la perturbación de lo que vive, como bien lo expone Mukařovský. Además, el objeto que se hace signo estético increpa a Castán y le dice esto eres tú, otro hombre que no eras antes del encuentro sensible, como lo plantea Gadamer, y le da un conocimiento del orden universal, desde su encuentro particular y parcial, como lo explica Kant. Es así que desde el epígrafe de Jean-Paul Sartre, que Castán elige en "Viernes. Octubre 16", "Ser libre no es querer hacer lo que se quiere, sino querer hacer lo que se puede.", las posibilidades del autor del diario, como las de sus acompañantes estarán supeditadas a lo que el encierro les permite, que irónicamente es más que lo que el afuera les confiere. En ese caso una de esas posibilidades es la de imaginar y sentir.

Pero no todo termina con la revelación que significaba el zapato. El milagro consistía en que este caminaba solo, hasta que Castán se percata de que este era accionado por las visitas ocasionales de una rata al interior del zapato. Este descubrimiento es el que efectivamente rompe con el milagro y es cuando la rata pasa a ser el objeto de la percepción del diarista. Así, desde su escritura, empieza a atribuirle a dicha rata una serie de cualidades y convenciones acerca de una clase de sujetos en la que él se incluye:

La rata es un animal acorralado. La rata es como yo [...] la rata es un perseguido [...] Somos de la raza de los que huyen,

así como el rechazo de lo alegórico y lo poético, como naturalezas verosímiles. 
del grupo de los que caen en trampas, de la especie de los que son cazados, de la familia de los que no deben vivir. (Zárate Moreno, 1980, pp. 16-17).

La exposición sobre su procedencia, que le es revelada solo por medio de la rata, proyecta a Castán como un sujeto susceptible de todo lo que le pasa a la rata. La ruptura del milagro no limita su percepción, sus posibilidades de crear, de pensar o de reflexionar. Al contrario, desde la proposición del epígrafe del día 16 de octubre hasta el cierre del mismo, Antón solo logra ser libre desde las posibilidades que le otorgan el espacio y las cosas que lo componen. Pero lo más interesante es que esta experiencia de carácter estético le proporciona una oportunidad meta-creativa -crear sobre lo creado-, propia de una operación sensible capaz de sobrepasar los conceptos dados, dentro de las experiencias posibles que concede el objeto.

Son, precisamente, los límites que le dan los objetos de su percepción los que permiten reconocer en la situación analizada que la experiencia es de carácter estético, pues las relaciones entre las cuestiones que sostienen las conclusiones de Castán tienen en sí un valor de carácter universal. Mientras que las proyecciones subjetivas le permiten el reconocimiento de sus limitaciones, los asuntos implicados en la disertación de su propio reconocimiento traen consigo los símbolos del desarraigo, de la marginalidad y de la injusticia, enraizados en la cultura occidental. En consecuencia, dichos puentes entre lo universal y lo singular son la evidencia de sus limitaciones y sus posibilidades. Por eso, para Castán la rata y el zapato son la puerta de entrada a su "vínculo recóndito" (Zárate Moreno, 1980, p. 16) -su ser milagroso y material-. Esta situación también le exterioriza al diarista la carne de su carne, su desnudez y su despojo, la "inquietud del espíritu” (p. 24), quizá como al mismo Ecce Homo de Nietzsche.

\section{UNA FLOR PARA LA SALVACIÓN: CONCRECIÓN DE LA EXPERIENCIA ESTÉTICA Y SU FUNCIÓN EN PRISIÓN}

Es evidente que la experiencia estética rebasa los límites del arte e interviene en la esfera cotidiana. Si hay algo sobre lo que la literatura reflexiona, en su esencia autotélica, es acerca del conocimiento de ese mundo íntimo, interior y trascendente de lo cotidiano. La novela como género del día a día no deja de escudriñar, encontrar y conjurar lo complejo de la existencia de sus personajes, que son los que estamos afuera de ella, tantos Gregorio Samsa o Bartleby en oficinas y filas de banco, tantos Johnny Carter encerrados en sus habitaciones o tantos Víctor Suaid que reformulan las calles y cruzan mundos disímiles. Es así que la experiencia estética es quizás uno de los temas más recurrentes de la narrativa, pues cuenta con apariciones constantes en cuentos y novelas.

La cuestión sobre este tipo de experiencia en la narrativa parte de mostrar a sujetos en el seno de su cotidianidad y el papel de la percepción estética en sus vidas ficticias. Es factible ver cómo la experiencia interior y creativa de tantos personajes transforma sus mundos en una iniciativa escapista. A pesar de que Kant en Crítica de la razón pura (2000), como posteriormente Arthur Schopenhauer en El mundo como voluntad y representación (2013), plantean que este tipo de vivencia no tiene un fin práctico, no deja de ser una realidad que la experiencia estética puede sacar al 
sujeto de algunos escollos de la vida diaria. Mukařovský considera al respecto:

En el caso de la relación social la importancia de la tendencia estética en tanto que ayudante y acompañante de la función práctica es especialmente evidente: la necesidad de atenuar conflictos, conseguir simpatías, conservar la dignidad personal y otras encuentran un apoyo en esa especie de placer desinteresado y plácido que acompaña a la postura estética. (Mukařovský, 1977, p. 150).

También Hans Robert Jauss (2002) propondría, como una de sus tesis sobre este tipo de conocimiento, que:

[...] la experiencia estética ha recibido, en el plano de la aisthesis, una tarea contra el mundo de la vida cada vez más instrumentalizado que no se había planteado hasta ahora en la historia de las artes: oponer a la experiencia atrofiada y al lenguaje servil de la sociedad de consumo una función crítica y creativa de la percepción estética $\mathrm{y}, \mathrm{a}$ la vista de la pluralidad de funciones sociales y de las versiones científicas del mundo, hacer presente el horizonte del mundo común a todos y que el arte puede visualizar como un todo posible o realizable. (P. 73).

Tanto en la escritura total del diario que se muestra en La cárcel, como la experiencia sensible sobre el zapato y la rata, se se expone, fuera de cualquier intención utilitaria, la ruptura de una existencia monótona. $\mathrm{La}$ escritura de Castán comprueba, por ejemplo, lo imprevisto de esta ruptura: “(...) como quien abre la llave del agua corriente
(...)" (Zárate Moreno, 1980, p. 10), como una puerta que rompe con "letargo del encierro" (p. 14). Aclaraciones en la escritura como las anteriores, que muestran lo involuntario de dicha percepción, refuerzan la idea de Mukařovský y Jauss: la experiencia estética es inesperada, se opone al servilismo del lenguaje, propone distintos horizontes posibles y por supuesto hace llevadera la existencia, tal como es sobrellevada la estadía de Antón en prisión -por lo que cumple una función o tarea en contra de la realidad que vive el personaje-.

Cabe analizar un poco más de cerca esta relación entre experiencia estética y su posible función en prisión. Diego Higuera Castillo explica, en Antón Castán y las representaciones del intelectual en La cárcel, de Zárate Moreno (2013), que el diarista espiritualiza su entorno desde su escritura, como revelación de un mundo construido a partir de su experiencia. Si bien el crítico propone, desde los planteamientos de Jan Patočka (1976) -acerca de los intelectuales-, que la espiritualización que hace Castán es un ejercicio intelectual en la búsqueda de presentar su realidad -más que representarla- (p. 20), la revelación de su visión del mundo demanda una condición primigenia. Es claro que Antón como sus compañeros de celda parodian a la figura del intelectual; asimismo es evidente que sí existe dicha espiritualización, no solo del espacio, también de sus recuerdos y de su mismo ser. Sin embargo, y contrario a lo que dice Higuera Castillo, esto es una actitud desintelectualizada.

Es prudente poner piso frente a lo que se concibe como espiritualización, dado a lo ambiguo que pueda resultar el término. En este caso, el crítico y teórico francés George Bataille, en La experiencia interior (1986), 
manifiesta que las cuestiones del espíritu radican en el cese de la actividad intelectual. Esta espiritualidad es parte de la experiencia interior, por lo que el discurso -el enunciado-, es un mero medio de expresión y por lo tanto un obstáculo como forma del intelecto. Así, dice Bataille, que en la experiencia espiritualizada "lo que cuenta no es ya el enunciado del viento, sino el viento" (p. 23). En este caso, la escritura de Antón Castán en La cárcel busca la presencia del objeto y no su representación, como lo afirma Higuera Castillo, pero no como producto primero del intelecto sino del espíritu.

Hay claras marcas en la escritura de Castán que muestran el momento anterior a la reflexión, como ya se ha ejemplificado en párrafos anteriores. La aparición y desaparición de lo que llama misterio lo confirman, en el caso del zapato y la rata. A pesar de que la escritura es un intento de intelectualizar su experiencia, pues esto implica recuerdo y selección de proyectar dicha memoria, las marcas de que esto es resultado de un encuentro fortuito entre objeto y sujeto son visibles. Si se lee el día "Sábado. Octubre 17", apartado del diario, se observa que la espiritualización del entorno, al margen de cualquier intento metaforizador e intelectual, resulta también de una posición especial, anterior a toda facultad reflexiva, frente a la misma realidad. En este día del diario, desde un tono anecdóti$\mathrm{co}$, se expone la curiosa labor de cultivo de una flor artificial que, junto a Braulio Coral, compañero de celda, el escritor del diario se dedica a cuidar. A pesar del procedimiento antitético que propone, el razonamiento de lo que significa la flor en prisión y el cuidado de la misma, resultado de una "broma botánica", termina siendo un ejercicio diario de dedicación:

Después de lavarme la cara, lo primero que hago es regar el rosal. Lo llamamos así, pero el rosal consiste en una rosa que siempre está viva, porque, siendo una rosa artificial, está destinada a demorarse en morir. Nunca supe cómo llegó la rosa a la prisión. Lo cierto es que llegó y que, como un tributo a la belleza del mundo, resolvimos conservarla en la celda. De todos modos, por ser espuria, era una flor apropiada para el ambiente de invernadero de la cárcel.

Más tarde a Braulio se le ocurrió que la plantáramos. En una taza de barro pusimos un poco de tierra y allí clavamos al alambre que imita el tallo de la rosa.

Se levanta gallarda sobre el puñado de tierra, pero por desgracia, cuando sopla algún viento furtivo, como cuando una persona pasa cerca de ella, la flor cruje como si quisiera recordarnos que en lugar de ser una rosa, no es más que una miserable banderita de papel. Plantarla tenía que llevar el paso técnico inmediato, es decir, cultivarla. Siguiendo con la broma botánica, he acabado por regarla todos los días. En este trabajo que exige habilidades hidráulicas de jardinería, una gota torpe puede desleírla. (Zárate Moreno, 1980, p. 20).

Primero, el narrador justifica el papel del rosal en la celda. Su proceder es desconocido; su conservación es la búsqueda de un fin idealista: la belleza. Lo que sucede luego de esta información que proporciona el diario es lo que significa la flor en el encierro. A esta explicación se suma una discusión 
acalorada que tiene Castán con David Fresno, otro de los compañeros de reclusión, justamente sobre la flor. El rosal -“tributo a la belleza del mundo" - no solo es signo de dicha belleza, es puerta a ese mundo de la belleza, por lo que se está ante el crisol donde sujeto y objeto se funden, y donde lo que en apariencia podría ser una práctica absur$\mathrm{da}$, es en realidad el posicionamiento de la visión particular del sujeto y un estallido de sentido: experiencia estética.

Ahora bien: ¿qué hace de este pasaje experiencia estética y qué elemento de la escritura de Antón Castán permiten determinarla como tal? A diferencia de otros textos donde este tipo de experiencia se muestra a través de una escritura mucho más contemplativa, en La cárcel esto se ve disimulado por una prosa de dimensiones filosóficas, que guarda el secreto del asombro. A pesar de que la manifestación del asombro es una constante en el texto, siempre se ve atenuada por la reflexión o crítica de Castán y los demás personajes, como ya fue analizado en el asunto de la rata. Pese a esto, los elementos de la experiencia estética son patentes: primero se ve la restitución del sujeto ante la práctica de jardinería. Como la rata o el zapato, la flor artificial vuelve sobre lo perdido, ese componente temporal del ciclo vital que la ilusión del cultivo de una flor proporciona en su proceso. En segunda instancia, la actividad de cultivo enriquece no solo a la figura del rosal al darle facultades naturales, también suma otra empresa a la vida monótona de Antón Castán en la cárcel. Y a pesar del explícito conocimiento de la artificialidad de la flor, su trabajo botánico es una forma de defraudar la realidad de la cárcel:
Riego la rosa, que empieza a envejecer, pero que aún se mantiene altiva, con sus postizas venas de savia fallecida, con sus pétalos disecados, de color de sangre falsificada. Varias gotas quedan temblando por un momento en la raíz de alambre. En aquel sitio la tierra parece rebelarse contra el fraude de nuestro ilusorio cultivo. (Zárate Moreno, 1980, p. 22).

Y si en la cárcel “Todos los días las cosas ocurren del mismo modo" (Zarate Moreno, 1980, p. 23), la broma botánica pasa a ser una forma particular de comprender la flor y de ver el mundo a través de ella. Ese puente a la belleza pone de manifiesto ese provecho que la función estética le provee a la vida, como interpreta Jan Mukařovský; esa "tarea contra el mundo de la vida" (2002, p. 73) que plantea Hans Robert Jauss. Así, la carga estética de la práctica de cultivo de la flor saca a Antón Castán y a Braulio Coral del escollo de la monotonía, conserva su humanidad en la cárcel, genera simpatías entre compañeros y consigo mismo y reafirma ese placer desinteresado de la actitud estética al no buscar fruto de esta actividad aparentemente absurda.

Lo precedente confirma que lo que no se encuentra en el objeto en sí mismo, y se halla en sus relaciones con el sujeto -como lo es una flor artificial y un sujeto en prisión-, radica del posicionamiento particular donde espacio y tiempo, como nociones fundamentales de manifestación de los fenómenos, propician lo que Kant llama la intuitus derivatitus, que en principio no es intuición intelectual (2000, p. 90). Es en este sentido que el intelecto se ve, en cierta medida, desplazado para darle carta blanca a la recepción sensible. En La cárcel esta construcción 
desintelectualizada, esta experiencia de riego de una flor artificial, consignada por Castán en los renglones de su diario, demuestra que ante una realidad mal hecha ${ }^{8}$, la experiencia estética permite agregar y romper con las paredes del encierro, o defraudar la realidad para acoplarse a ella.

\section{Del absurdo a un espacio PARA LA EXPANSIÓN: "LA LIBERTAD ES LA CÁRCEL"}

Otro componente que hace resonancia en algunos comentarios sobre la obra de Jesús Zárate Moreno es la presencia del absurdo. La atmosfera kafkiana y una escritura cosmopolita, son ingredientes que analistas del canon literario colombiano, críticos de la literatura y algunos compiladores de antologías de cuento nacional, exaltan a la hora de ubicar la obra del autor colombiano:

Específicamente, La cárcel recrea la problemática de una época, la injusticia, pero de una manera existencial. El absurdo de un hombre -Antón Castán-, detenido y encarcelado durante tres años por el único delito de no haber cometido delito, es la sátira elegante, metaforizada y cargada de humor negro contra la institución carcelaria y contra los hombres que administran injusticias. (Cinep 1998, p. 67).

El absurdo como característica que deriva de esta mezcla notable entre universalidad

8 La prueba expresa dentro de la novela, sobre la consideración de la realidad como algo mal hecho, aparece en la misma fecha, "Sábado. Octubre 17": "Me encuentro de nuevo, al amanecer, en el rincón donde un ensayo frustrado de pared ha dado lugar a que se coloquen allí un aguamiel de metal y los cubos higiénicos" (p. 19). La redundancia de ensayo y además frustrado dice mucho sobre la realidad que le toca vivir a Antón Castán en el encierro. y un ambiente extraño, propone en La cárcel, además del asentamiento de una crítica a la justicia y el comportamiento humano, la posibilidad de ver la subjetividad de sus personajes y sus conjeturas sobre la realidad. Así, la novela ahonda en la individualidad del autor del diario y en su escritura desde la construcción del absurdo, que complementa la realidad de Antón Castán y por supuesto su percepción de la misma.

Para Gilles Deleuze, en la Lógica del sentido (1994), el absurdo es “(...) lo que no tiene significación, lo que no puede ser ni verdadero ni falso" (p. 20). El filósofo francés propone cuatro paradojas dentro de la naturaleza del sentido, en donde la Paradoja del absurdo, o de los objetos imposibles designa la enunciación de objetos que en su construcción son contradictorios. A pesar de tal contradicción, estos objetos tienen sentido, pero su significación se desvanece a causa de su imposibilidad. Esta cualidad de los llamados objetos imposibles está dentro de lo que Deleuze llama los estraexistentes, acontecimientos ideales inefectuables, los cuales estriban entre un mínimo de lo real, de lo posible y de lo imposible (p. 36). Estos objetos son producto de las mediaciones del "extra-ser" y Deleuze los propone a partir de los planteamientos kantianos de las posibilidades del conocimiento, tanto trascendental como crítico.

En este caso, el absurdo en La cárcel se erige desde las contradicciones a las que el tiempo, el espacio y los demás objetos del diario están subordinados. Con un humor riguroso, una de las contradicciones que se lee en la novela es la noción de prisión. Desde las primeras páginas del diario se puede distinguir un sujeto que por su lucidez tiene la libertad y los medios necesarios 
para expresarse. Ante tales condiciones, no es extraño que tras la libertar aparezca la noción del disfrute y del confort, algo a lo que quizá los personajes de la obra hacen alusión constante: "Se disfruta aquí, en cierto modo, de alguna comodidad" (Zárate Moreno, 1980, p. 31). Al respecto, el crítico y escritor Germán Arciniegas proponía en su artículo "Gatorpardo a la colombiana" (2003), que en La cárcel "Nada queda en pie", al referirse a la política, al Estado, a la Iglesia y a la justicia, entre otros aspectos. Y sumado a esto afirmaba: "Se diría que el único rincón de Colombia en donde se habla con toda libertad es en la celda donde el autor y tres detenidos más desmontan la comedia humana a su antojo" (párrafo 2).

Al ser la cárcel un espacio dispuesto para que quienes hayan cometido un delito pierdan la libertad, el goce, su opinión y la posibilidad creativa9, La cárcel se presenta como una parábola absurda sobre la libertad en el encierro. De hecho, la novela muestra en repetidas ocasiones la figura del oxímoron como forma básica del absurdo: "La libertad es la cárcel" (p. 51) o como reza el epígrafe del día "Jueves. Octubre 22": "La libertad es la prisión del hombre libre" (p. 49). En ese caso, el absurdo, desde las observaciones de Deleuze, plantea en La cárcel un marco plausible en donde el autor del diario -Castándespliega todas sus posibilidades sensibles y logra reflexionar sobre temas universales de la condición humana.

9 Al respecto, Foucault, en su conocido trabajo Vigilar y castigar. Nacimiento de la prisión (2003), propone que más allá del castigo corporal, se busca la lesión del alma: "A la expiación que causa estragos en el cuerpo debe suceder un castigo que actúe en profundidad sobre el corazón, el pensamiento, la voluntad, las disposiciones. Mably ha formulado el principio, de una vez para siempre: 'Que el castigo, si se me permite hablar así, caiga sobre el alma más que sobre el cuerpo'”. (P. 18).
Y a pesar de que en prisión hay restricciones y todos allí se saben prisioneros, el espacio y el tiempo se ven sometidos a una serie de contradicciones capaces de plantear, si no el significado real de la cárcel, el sentido de un espacio y tiempo propicios para extender todas las discrepancias a las que el ser humano está subyugado. Esta ambivalencia de la cárcel como espacio de reclusión, tiempo de purga y territorio de la libertad interior, son elementos tangibles para proponer la imposibilidad de ser en un mundo en donde las fronteras se difuminan. Es por eso que al leer La cárcel no solo se está frente a una propuesta estética de dimensiones universales y cosmopolitas, sino también ante una propuesta de dimensiones filosóficas. En ese caso, la experiencia estética adquiere un lugar preponderante dentro del universo de la novela, pues Castán advierte que: "En la cárcel el tiempo se siente, como se siente un dolor" (Zárate Moreno, 1980, p. 60) -intuición interna-. Por su parte, el espacio, como condición externa de los fenómenos, se problematiza a medida que las acciones en este pierden su principal utilidad e identidad.

\section{Conclusiones}

No hay duda que la obra de Jesús Zárate Moreno, incluida su novela La cárcel, rompe con el canon literario santandereano de su época. A pesar de su poca notoriedad -irónicamente con un premio tan prestigioso como el de la editorial Planeta-, ha añejado clandestinamente de manera excepcional. Además, al ser La cárcel una novela tan cercana a la filosofía, como bien lo afirma Juan Diego Serrano Durán (2016, p. 51), el problema del hombre frente a una realidad que debe reformular para sobrellevarla adquiere 
significativamente más sentido. Además, dice mucho la escritura sobre la evasión de la realidad o la búsqueda de otros caminos a partir de ella, esto si contamos con las circunstancias de su campo literario: un país donde la política se debatía entre los extremos del Frente Nacional, la inestabilidad legislativa y judicial y la literatura de corte naturalista -en su mayoría-.

Claramente, los planteamientos kantianos sobre la experiencia sensible son indispensables para la lectura de la experiencia estética de Antón Castán. Su percepción le permite al personaje encontrar otras posibilidades que le restauran su identidad, su sentido de la reflexión y en general su sentido de la vida. Es a partir de la ruptura de las convenciones del espacio, del tiempo y de la naturaleza de los objetos, propiciadas por un conocimiento a priori, que el diarista logra conformar una visión de mundo que rompe con las paredes del encierro. Estas adiciones de sentido vivifican lo inerte y el significado de lo dado.

Mientras la prisión busca terminar con lo que se considera libertad, la posición estética de Antón Castán rompe con el paradigma de la cárcel, tanto así que a su salida de prisión siente dejar allí su inocencia, la que compartió con David Fresno, Braulio Coral, Antonio “El Honorable Gordo Tudela" y Mister Alba. Este punto es cardinal porque el autor propone el doble juego de la condición del hombre en prisión: el que depende de la cárcel para ser lo que cree ser y el que se construye a partir de la misma. En los dos casos Castán se ubica en una zona ambigua, ora por las capacidades imaginativas que explotó en el encierro, ora por la dependencia de unas condiciones para la manifestación de dichas capacidades. Lo interesante del problema que plantea Zárate Moreno es que aun cuando a la experiencia estética no se le considera conocimiento pragmático, no cabe duda, luego de analizarla desde los acercamientos de Kant (2000), Mukařovský (1977) y Jauss (2002), que su importancia en la vida otorga posibilidades vitales para sobrellevar la existencia.

En el caso de la presencia del absurdo -la dinámica de la paradoja de los objetos imposibles-, la configuración del espacio permite un giro de tuerca en la posesión que hace el sujeto de los lugares y los cuerpos que allí habitan. Donde la prisión es castigo, Zárate Moreno la muestra como oportunidad y libertad, pero no por sus "bondadosas" barreras, cadenas y rejas, sino por las competencias del mismo hombre-recluso que la habita. En cierta medida el encierro le da a Antón Castán un conocimiento de sí mismo, de sus compañeros y de su realidad. Esto quiere decir que ante la paradoja que plantea la novela -los diálogos y las descripciones que construyen el absurdo-, los espacios y los objetos se aprovisionan de una condición particular, distinta a la de sus propiedades prácticas. Este conocimiento sensible es el mismo que Castán y compañía perciben y traducen en objetos nuevos, con alcances inéditos que proporcionan diferentes puertas hacia una comprensión de corte sensible.

A su vez, la afección de la materia de la realidad por parte del sujeto, y viceversa, es traducida por Zárate Moreno en una escritura que, en varios pasajes de la novela, busca la desintegración del instante. Dado a la desintelectualización del relato de su experiencia, Antón Castán, el diarista y protagonista de la novela, carga de sí mismo -de su individualidad-al espacio, al tiempo y a 
los objetos. Tal práctica le revela al protagonista de La cárcel su relación con el mundo y sus posibilidades íntimas de expansión, aspectos que le ayudan a soportar y aceptar la vida en el encierro, incluso sabiéndose inocente y luego vengado.

Me siento libre, con una libertad que me sobra en el cuerpo, con una felicidad morbosa que palpita dentro de mí de un modo extraño. Sin embargo, comprendo que en adelante, por donde quisiera que me lleven mis pasos, ya no podré ser libre, con esa libertad alegre y descansada que proviene de la inocencia.

Cargado todavía el garrote homicida, comprendo que con lo que he hecho, Dios acaba de separarse de mí. Comprendo que el Señor acaba de darme la vida por cárcel. (Zarate Moreno, 1980, p. 179).

Es así que las reflexiones de La cárcel sobre temas fundamentales de la condición humana son producto de este conocimiento y relevancia de la sensibilidad humana, así como de los factores que la estimulan. Jesús Zárate Moreno no solo hace en su novela una crítica a diversos temas políticos y sociales, también propone una exposición ontológica y fenoménica de las posibles rutas ante el hecho de vivir.

\section{ReFERENCIAS}

Arciniegas, G. (2003). Gatopardo a la colombiana. Diario El Tiempo. Recuperado de http://www.eltiempo.com/archivo/ documento/MAM-1008651.

Bataille, G. (1986). La Experiencia interior: seguida de Método de meditación; y de Post-scriptum 1953. Madrid, España: Taurus.
Cinep. (1998). Absurdos y realidades. En Colciencias (ed.), Colombia país de regiones. II, (pp. 153-154). Bogotá, D. C., Colombia: Cinep-Colciencias.

De Man, P. (1991). La autobiografía como desfiguración. Suplementos Anthropos, (29), 113-117.

Deleuze, G. (1994). Lógica del sentido. [Archivo PDF]. Santiago de Chile, Chile: Edición Electrónica de www.philosophia. cl/Escuela de Filosofía Universidad ARCIS. Recuperado de: http://www.medicinayarte.com/img/biblioteca_virtual_ publica_deleuz_logicasdelsentido.pdf

Gadamer, H. G. (1996). Estética y hermenéutica (1964). Daimon: Revista Internacional de Filosofía, (12), 5-12.

Higuera Castillo, D. (2013). Antón Castán y las representaciones del intelectual en La cárcel, de Zárate Moreno. En D. Higuera Castillo, J. F. Caballero Hernández y M. Castillo Fuentes (eds.), Tres escritores santandereanos (pp. 9-76). Bucaramanga, Colombia: Colección Temas y Autores Regionales UIS.

Jauss, H. R. (2002). Pequeña apología de la experiencia estética. Barcelona, España: Paidós.

Kant, I. (2000). Crítica de la razón pura. Madrid, España: Alfaguara.

Foucault, M. (2003). Vigilar y castigar. Nacimiento de la prisión. Buenos Aires, Argentina: Siglo Veintiuno Editores.

Mukařovský, J. (1977). Escritos de estética y semiótica del arte. Barcelona, España: Gustavo Gili.

Nieto Lascarro, Y. A. y Orduz Rodríguez, F. (2017). El metateatro en La cárcel de Jesús Zárate Moreno: un proceso a la justicia. Revista Lingüística y Literatura, (72), 174-191. DOI: https://doi.org/10.17533/ udea.lyl.n72a09 
Pérez Pinzón, L. R. (2018). Literatura santandereana. Visibilidad, concepciones y evocaciones. Estudios de Literatura Colombiana, (43), 137-154. DOI: https://doi. org/10.17533/udea.elc.n43a08

Picard, H. R. (1981). El diario como género entre lo íntimo y lo público. Biblioteca Virtual Miguel de Cervantes. Anuario de la Sociedad Española de Literatura General y Comparada, (4), 115-122.

Serrano Durán, J. D. (2016). El hombre que no conocimos. Revista de Santander, (11), 24-63. Segunda Época, División de Publicaciones UIS.

Schopenhauer, A. (2013). El mundo como voluntad y representación. Madrid, España: Editorial Trotta.
Todorov, T. (1981). Introducción a la literatura fantástica. México D. F., México: Premia Editora de Libros S. A.

Torres, O. R. (2003). "Aldea”, un poema de Darío Samper: aproximación estética y artística. Litterae: Revista de la Asociación de Exalumnos del Seminario Andrés Bello, (12), 49-72.

Zárate Moreno, J. (1980). La cárcel. Madrid, España: Planeta.

Zárate Moreno, J. (2016). La cárcel. Bucaramanga, Colombia: Universidad Industrial de Santander - Fusander, Fundación Santandereana para el Desarrollo Regional. 